\title{
How Elephants Learn the New Dance When Headquarters Changes the Music: Three Case Studies on Innovation Strategy Change
}

\author{
Serdar S. Durmuşoğlu, Regina C. McNally, Roger J. Calantone, and \\ Nukhet Harmancioglu
}

\begin{abstract}
Does a product innovation strategy change at company headquarters resonate the same way at different strategic business units (SBUs)? What factors play a role in differing implementation of new innovation strategies? A collective case study was conducted at three SBUs of an international conglomerate to investigate why the SBUs implement the same corporate innovation charter in vastly different manners, both in strategic processes and in organizing for new product development (NPD). This study's contribution to the literature is twofold. First, it develops initial insights into how three SBUs implement diverse SBU-level innovation strategies in response to the same product innovation charter. Second, it extends the findings of previous studies on NPD strategy by presenting how three SBUs reshape their structure and resource allocation, changing various dimensions of their innovation strategy while also fitting the competitive structure in their individual, non-high-tech, traditional manufacturing industries as they respond to the corporate mandate. In this study, several factors were observed to influence a firm when formulating a new product innovation strategy. First, past performance and strategic typology constrain the innovation paths available. Poor past performance limits available resources whereas the strategic typology managers use limits their ability to recognize other opportunities. Next, capacity constraints provide a catalyst in moving toward process improvements. Third, management involvement in the day-to-day implementation of change is necessary to ensure that the new processes are implemented. Finally, corporate performance metrics are quite influential in how SBUs adapt to change. This study identifies that even with the immense power corporate has over these SBUs, some still dance to their own tune, ignorant of their deviation from the corporate mandate because the metric is not sufficient to detect these deviations. This study suggests the use of multiple types of metrics to minimize the likelihood of nearsighted responses to innovation charter changes.
\end{abstract}

\section{Introduction}

B

usiness strategy, the pattern or plan that integrates a firm's major objectives and action sequences into a cohesive whole (Mintzberg

Address correspondence to: Serdar S. Durmuşoğlu, Department of Management and Marketing, University of Dayton, 703 Miriam Hall, 300 College Park, Dayton, OH 45469-2271. Tel.: (937)229-3540. Fax: (937)229-3788. E-mail: durmuser@udayton.edu. et al., 2003), has been investigated from various theoretical perspectives. For example, contingency theory posits that, to achieve high levels of performance, firms must match strategies to environmental conditions (Ginsberg and Venkatraman, 1985). Consequently, firms need to change to adapt to their environments because environmental conditions continuously evolve (Miles et al., 1978). In fact, de Geus (1997) notes that one common characteristic of firms 
that endure more than a century is that they are sensitive to the environment in which they operate.

Some organizations, such as the ones in this study, tend to exhibit relatively long periods of stable strategies and structures because they delay change until absolutely necessary rather than adapting continuously to the environment. Abrahamson (2004) labels such firms as change avoiders, noting that these firms have to undergo rapid, relentless change or face extinction. When firms delay change to this extent, painful and system-wide shifts are generally required to survive (Tushman, Newman, and Romanelli, 1997).

Changing a product innovation strategy, which is a subset of a firm's overall business strategy, requires changes in organizations' operational modes. However, attempts at changing organizational routines and processes are often clouded by the firm's prior success or are poorly implemented (Tushman, Anderson, and

\section{BIOGRAPHICAL SKETCHES}

Dr. Serdar S. Durmuşoĝlu is assistant professor of marketing in the School of Business Administration at the University of Dayton. He earned his Ph.D. in marketing from Michigan State University in East Lansing. He also holds an M.B.A. from Purdue University in West Lafayette, Indiana, and a bachelor's in mathematics from Boĝaziçi University in Istanbul, Turkey. In addition, he has several years of corporate work experience. Dr. Durmuşoĝlu's main research area is new product development (NPD), with special interest in NPD strategy and product innovation decisions, interaction of NPD teams with internal departments and external parties, and the effect of information technology on NPD. His work has been published in Industrial Marketing Management, R\&D Management, and the Journal of Product and Brand Management, among others.

Dr. Regina McNally is assistant professor of marketing in the Department of Marketing and Supply Chain Management at The Eli Broad Graduate School of Management at Michigan State University. She received a Ph.D. in business, specializing in marketing, from the University of Illinois at Urbana-Champaign. Her research interests focus on the processes and outcomes of strategic firm decisions, such as new product development, investigating the factors that drive the choice of different alternatives and the performance outcomes of such decisions. Of special interest is the role of both economic factors and social factors in such decisions.

Dr. Roger Calantone, NPDP, is the Eli Broad University Professor of Business at Michigan State University. He is also adjunct professor of economics and director of the program in information technology management. His research is focused on product innovation strategy and decision making.

Dr. Nukhet Harmancioglu is assistant professor of marketing in the Faculty of Business Administration at Bilkent University in Bilkent, Ankara, Turkey. She earned her Ph.D. from Michigan State University in East Lansing. Her research interests span the fields of strategic marketing management, new product development, and international business. She was the recipient of the 2005 Product \& Development Management Association Dissertation Proposal Competition
O'Reilly, 1997). Belasco (1990) metaphorically compares firms being trapped by their successful pasts and continuing to operate in the old ways to elephants being shackled when they are young so they learn to obey. These elephants do not break their chains when they grow, despite having the strength to do so easily. In organizations, Miller (1991) provides eminent examples of top managers getting "stale in the saddle," who continue with the same set of strategic moves that made them initially successful, despite driving their current businesses to ruin in the face of a changing competitive environment. In the new product development (NPD) realm, some firms rigidly continue to use the sets of values, skills, and managerial and technical systems that served them well in the past even when these values, skills, and systems have become inappropriate in the new environment (Leonard-Barton, 1992; March, 1991).

Based on a collective case study at three U.S.-based strategic business units (SBUs) of a major international manufacturing conglomerate, which is hereafter referred to as corporate, this article presents the story of three elephants trying to break their chains and learn to dance to the new rhythm: Despite past success and institutionalization of the profitable habits that enabled success, they must learn to grow their business via innovation.

The core common scenario in this study is the following: Driven by a change in financial markets and analysts' expectations, the top-management team of a conglomerate decided to abandon the strategy of growing via mergers and acquisitions. Instead, they advocated top-line growth through NPD as the primary key to success. They supported this strategic redirection via changes in the corporate product innovation charter and encouraged increased intellectual property (e.g., patents), compelling SBU managers to follow the change in the parent company's strategy. Subsequently, the subsidiaries attempted to change certain dimensions of their innovation strategy with a top-down approach to adapt to the corporate mandate. The result is that the three divisions now have diverse SBU-level strategies. Extant literature describes that SBU innovation strategies can be vastly different from the corporate innovation strategy (Firth and Narayanan, 1996). This study extends extant knowledge by exploring how SBUs that are adapting to a new corporate innovation strategy implement diverse SBU-level strategies.

Based on contingency theory, Barczak (1995) posits that a firm's choice of new product strategy, struc- 
ture, and processes are interrelated. Moreover, the performance of an NPD program is determined by a firm's innovation strategy as well as its capabilities and organizational structure (Clark and Wheelwright, 1993). Previous studies have examined new product strategy in high-technology industries (e.g., Barczak, 1995; McGrath, 2001; Meyer and Roberts, 1986). Another contribution of this study is to explore how three SBUs change certain dimensions of their innovation strategy and reshape their structure and resource allocation as they respond to the corporate mandate in traditional, non-high-tech industries.

The remainder of the article is organized as follows. First, an overview of innovation strategy literature that conditioned the observational priors of the authors is provided, and then a clear picture of what happened in the three SBUs examined is drawn. Next, similarities and differences are identified between these organizations to develop some insights about why things occurred the way they did. Finally, the article concludes with managerial implications and recommendations.

\section{Background: Drivers of NPD Program Success and Product Innovation Strategy}

Product innovation or NPD strategy, the major focus of this study, is one of the main drivers of NPD performance (Cooper and Kleinschmidt, 1995). NPD strategy includes the goals for the firm's total product development efforts; the role of new products in relation to the firm's overall strategy; selection and prioritization of the customer markets, technologies, and product categories; and a financial and human resource deployment plan for NPD efforts (Cooper, 1993).

NPD strategy consists of two distinct components: technology strategy and marketing strategy (Nystrom, 1985). Technology strategy identifies the manner in which new products are developed, encompassing the two subcomponents of technology use and technology orientation. Technology use refers "to the way technologies are applied to the critical technical problems in product development" (ibid., p. 26). When development focuses on a given established area of technology, technology use is said to be isolated. On the other hand, synergistic technology use occurs when research and development (R\&D) for new products combines different technologies. Similar to technology use, technology orientation has two dimensions: internal and external. Whereas internal technology ori- entation refers to self-reliance by the innovating firm, an external orientation results in the innovator utilizing technology from outside the firm while developing new products. An externally oriented strategy would allow for outsourcing at some NPD stages. For example, a firm might employ a market research firm to conduct focus groups in the concept testing phase.

Marketing strategy is composed of three subcomponents: product focus, customer focus (Nystrom, 1985), and competitor focus (Urban and Hauser, 1993). If a company develops new products that are variations of existing products, the firm is concentrating on product modification. Conversely, if new products offered by a firm fall outside its established product lines, then this company's product focus is product diversification. Regarding customer focus, targeting existing customers is categorized as defensive whereas targeting new customers is offensive. Competitor focus can either be reactive or proactive. A reactive strategy is "based on dealing with situations as they occur, whereas a proactive strategy would explicitly allocate resources to preempt undesirable future events and achieve goals" (ibid., p. 19). Specific reactive strategies include defensive, imitative, second but better, and responsive, whereas proactive strategies include research and development, marketing, entrepreneurial, and acquisition and alliances.

Other elements that play an integral role in the success of a firm's NPD program are the existence of a formal and proficient NPD process; the way the firm organizes for NPD; the firm's culture and climate that support teamwork and encourage employee generation of product ideas; reward systems (including treatment of failure); and senior managers' involvement and communication of a clear message about the importance of NPD for the firm (Cooper and Kleinschmidt, 1995).

This brief summary of NPD strategy captures the factors that are used to compare and contrast the SBUs comprising the case study sample. The next section summarizes the research method employed, while the following section summarizes the SBUs per the NPD strategy dimensions just described.

\section{Method}

\section{Collective Case Study}

A collective case study method is utilized (Stake, 1995). Case-study research is advantageous when a 
"how" or "why" question is being asked about a set of events over which the investigator has no control (Yin, 1994). Moreover, the case-study method is appropriate in situations "where respondents cannot verbalize the underlying causes of behavior reliably" (Bonoma, 1985, p. 202). Therefore, the case-study method is appropriate to answer the research question of how do different SBUs of a corporation adapt to corporate innovation strategy change?

\section{Site Selection}

One investigator contacted the corporation's topmanagement team to request access to three SBUs as the case-study sites. To obtain various perspectives on the phenomenon being studied (Cresswell, 1997), the investigators requested that the SBUs compete in different markets. Although the specific SBU markets differ, their products are all categorized as building materials.

\section{Data Collection}

This study was conducted in three stages. First, to identify the initial response state to the corporate strategy change, two people at each subsidiary were asked to complete a survey. The survey items are based on Cooper (1993). The SBU key contacts, all of whom were executive managers, chose the survey respondents based on the guideline that respondents be senior managers knowledgeable about their SBU's innovation strategy. The initial mailing was followed one month later with a reminder e-mail and follow-up phone calls to the key contacts. Seven surveys were returned, two from two SBUs and three from one SBU. To limit any bias during the second stage of data collection, the survey results were not examined until after the second stage was completed.

In the second stage, field interviews were conducted with employees at the three SBUs to understand how the information and ideas flow between managers and NPD team members and how the SBU's senior managers ensure that the NPD implementation aligns with the SBU strategy. To enhance the understanding of the managers' personal experiences with the change process and the meaning they make of that evolution (Seidman, 1998), in-depth interviews with seven managers in the three SBUs were conducted. To gain multiple perspectives, at least one participant from marketing and one participant from the R\&D or NPD departments were interviewed. Informant titles are listed in Table 1. As convergence of opinions from multiple researchers enhances precision in findings and different insights add to the richness of the data (Eisenhardt, 1989), at least two of the investigators were present in every interview.

Based on prior literature (Cooper, 1993; Cooper and Kleinschmidt, 1995; Cooper, Edgett, and Kleinschmidt, 2001; Crawford, 1980), a standard interview protocol was developed to guide the interviews. The open-ended questions included in the semistructured interview protocol are listed in Table 2 . The interview protocol was semistructured in that the investigators refrained from following it to the letter. Informants were therefore encouraged to talk freely without feeling pressure to provide the "right answers." The interviews lasted between one hour and one and a half hours, were audio-recorded (unless the respondent requested otherwise), and subsequently were transcribed.

Once the interviews were completed, the researchers worked together to produce a set of combined field notes for each SBU. The combined field notes were based on field notes and materials gathered on site (e.g., organization charts, lists). To develop the combined field notes, each investigator first wrote an individual case note summarizing the information from all informants at a single SBU. Then, one investigator integrated the individual case notes from each SBU into a combined case note. The investigators met to finalize the combined case note document by discussing and agreeing on information to fill in gaps. Gaps

Table 1: Informant Titles

\begin{tabular}{|c|c|c|c|}
\hline & SBU1 & SBU2 & SBU3 \\
\hline Informant 1 & $\begin{array}{l}\text { Vice President of Marketing and } \\
\text { Product Development }\end{array}$ & $\begin{array}{l}\text { Director of Manufacturing } \\
\text { Services/Product Management }\end{array}$ & Senior Vice President, Marketing \\
\hline Informant 2 & $\begin{array}{l}\text { Senior Director of Product Development } \\
\text { and Engineering }\end{array}$ & Program Manager & $\begin{array}{l}\text { Senior Vice President, Technology } \\
\text { and Purchasing }\end{array}$ \\
\hline Informant 3 & & Senior Product Manager & \\
\hline
\end{tabular}




\section{Table 2: Interview Protocol}

1. Do you set a strategic agenda for NPD programs? If so, how is it set? Also, what are the (a) financial, (b) market, and (c) product portfolio goals and specifically, metrics?

2. Do you guide the cross-functional teams in their NPD activities based on a strategic agenda? Are goals also set for individual development projects?

3. How do you communicate these goals to the development teams? That is, what are the items/steps/routines followed while communicating the goal to the NPD teams?

4. How do you make sure that the goals are communicated effectively and that the development processes are proceeding in the right direction? That is, are there any metrics determined to monitor and control NPD projects?

5. Can you give an example where you guided the cross-functional teams in their NPD activities based on a strategic agenda for an individual project?

6. In general, what are the strengths and weaknesses of your firm in strategic agenda setting?

7. In general, what are the strengths and weaknesses of your firm's NPD process?

and conflicts were resolved by further reviewing the transcripts and by consultation with the SBU managers. Finally, informants reviewed the combined case note to ensure the investigators' comprehension of the situations is correct. The case notes were modified based on informants' comments. The transcriptions and combined case notes comprise the data analyzed to address the research questions. The next section reviews the analysis results.

\section{The Response of the SBUs to the Product Innovation Strategy Change Mandate}

NPD projects should be consistent with the articulated innovation strategy (Cooper et al., 2001). To ensure consistency and coherence across the technology and marketing components of a firm's NPD strategy, top management must link the components with the NPD strategy to guide employees as they implement the firm's goals and objectives (Clark and Wheelwright, 1993). A product innovation charter (PIC) serves this purpose. A PIC is a microlevel organizational concept with specific sets of organizational policies, objectives, guidelines, and restrictions (Crawford, 1980). By unifying the elements of the NPD strategy, the PIC guides a firm's set of activities aimed at developing new products and provides clear direction. A PIC typically includes the target business arenas, the goals of product innovation (including quantitative metrics), the activities to achieve the goals, the strengths to exploit, and the weaknesses to avoid (ibid.).

In the case studies, the corporate strategy change resulted in a mandate that the SBUs must grow via new products. This strategy change was communicated to the SBUs via a new PIC. Moreover, the strategy change was announced to research analysts at public meetings and was posted on the corporate website. The mandate requires that a specific percentage of annual revenues be generated from products introduced within a predetermined number of prior months. The fieldwork at each SBU was conducted approximately one year after this top-down mandate was instituted. This section describes the changes that occurred in the innovation strategies at each SBU. SBU characteristics are listed in Table 3, and the innovation strategies of the SBUs before and after the corporate mandate are described in Tables 4 and 5 . Finally, the organizational and NPD process changes that were implemented are summarized in Table 6. To ensure anonymity, the SBUs are identified by number.

\section{$S B U 1$}

SBU1 operates in a moderately competitive environment. In fact, it does not face any U.S. competition in its core products, where it has dominant market shares in several segments of a fragmented market. Recently, however, foreign firms have entered the U.S. market and started competing on price.

Executives at SBU1 indicate that customers are better at telling them "what they need" than "how the new product should be designed." SBU1's primary customers value products that make their job quicker by simplifying their work because they are paid by the job, not by the hour. Before the corporate mandate, SBU1's market strategy had been defensive in the customer focus dimension and product modification in the product focus dimension. SBU1 had an established NPD process and had been introducing products with slight modifications and incremental innovations to its existing customers. These innovations even resulted in this subsidiary receiving several innovation awards from corporate. 
Table 3: SBU Characteristics

\begin{tabular}{|c|c|c|c|}
\hline & SBU1 & SBU2 & SBU3 \\
\hline $\begin{array}{l}\text { Market Share in Its Target } \\
\text { Segments }\end{array}$ & Dominant & Nondominant & Dominant \\
\hline Annual Sales & $>\$ 300$ million & $>\$ 650$ million & $\begin{array}{l}\text { Not disclosed due to confidentiality } \\
\text { requirements }\end{array}$ \\
\hline Number of Employees & 1,400 & 4,000 & \\
\hline $\begin{array}{l}\text { Length of Time as SBU of the } \\
\text { Corporate }\end{array}$ & About 20 years & About 20 years & Less than 5 years \\
\hline $\begin{array}{l}\text { Motivations for Innovation } \\
\text { Strategy Change }\end{array}$ & $\begin{array}{l}\text { Compliance with corporate } \\
\text { mandate } \\
\text { Maintain market dominance }\end{array}$ & $\begin{array}{l}\text { Compliance with corporate } \\
\text { mandate } \\
\text { Retain current customers } \\
\text { (Customers have been asking } \\
\text { for new products that the } \\
\text { competition offers) }\end{array}$ & $\begin{array}{l}\text { Compliance with corporate mandate } \\
\text { Maintain market dominance }\end{array}$ \\
\hline Previous Change Programs & $\begin{array}{l}\text { Once, but small in scope } \\
\text { (i.e., only two departments } \\
\text { involved) }\end{array}$ & None & None \\
\hline Management Style & Formal & Formal & Informal \\
\hline
\end{tabular}

In its NPD efforts, SBU1 exhibited isolated technology use, as the development efforts involved utilization of the firm's established technology. Finally, this subsidiary relied solely on its own product engineers for NPD activities. Therefore, SBU1 had an internal focus to product development in terms of technology orientation.

At the time of the interviews, SBU1 was changing its NPD process. First, three new stages were being added to the front end of the process. This was done to incorporate marketing input and to clearly define the customer needs at the early stages of product development. An executive at SBU1 described the reason for change in the NPD process:

Product development didn't have marketing input. It wasn't driven by what was going on in the market place;
I don't know where the ideas came from. But, what would happen is, engineering would start the process, the concept development and that could go on for years. You know, because they never had any parameters, somebody would say we need a new [product] now. So, they would just come up with twenty designs. So, what we are trying to do now is let our product development process be driven by marketing.

Another change taking place was in the subsidiary's organizational structure. To fully incorporate marketing's input in NPD, the engineering and marketing departments were integrated into a single entity. To facilitate this integration, these two departments were colocated. The new department was named "marketing and product development." The engineers and marketing personnel are now assigned to an NPD

Table 4: Changes in Technology Strategy Dimensions of Product Innovation Strategy

\begin{tabular}{|c|c|c|c|c|c|c|}
\hline & \multicolumn{2}{|c|}{ SBU1 } & \multicolumn{2}{|c|}{ SBU2 } & \multicolumn{2}{|c|}{ SBU3 } \\
\hline & Before & After (Intended) & Before & After & Before & After (Intended) \\
\hline Technology & Isolated: & Synergistic: & Isolated: & Isolated: & Isolated: & Synergistic: \\
\hline Use & $\begin{array}{l}\text { Used the } \\
\text { established } \\
\text { technology }\end{array}$ & $\begin{array}{l}\text { Intend to } \\
\text { combine new } \\
\text { technologies with } \\
\text { old ones }\end{array}$ & $\begin{array}{l}\text { Used the } \\
\text { established } \\
\text { technology }\end{array}$ & $\begin{array}{l}\text { Will continue } \\
\text { using the same } \\
\text { technology }\end{array}$ & $\begin{array}{l}\text { Used the } \\
\text { established } \\
\text { technology }\end{array}$ & $\begin{array}{l}\text { Intend to } \\
\text { combine new } \\
\text { technologies with } \\
\text { old ones }\end{array}$ \\
\hline Technology & Internal: & External: & Internal: & Internal: & Internal: & External: \\
\hline Orientation & $\begin{array}{l}\text { Relied solely } \\
\text { on their own } \\
\text { personnel }\end{array}$ & $\begin{array}{l}\text { Intend to } \\
\text { outsource radical } \\
\text { innovations to } \\
\text { corporate }\end{array}$ & $\begin{array}{l}\text { Relied solely } \\
\text { on their own } \\
\text { personnel }\end{array}$ & $\begin{array}{l}\text { Will continue } \\
\text { relying solely } \\
\text { on their own } \\
\text { personnel }\end{array}$ & $\begin{array}{l}\text { Relied solely } \\
\text { on their own } \\
\text { personnel }\end{array}$ & $\begin{array}{l}\text { Intend to involve } \\
\text { experts outside } \\
\text { the firm }\end{array}$ \\
\hline
\end{tabular}


Table 5: Changes in Marketing Strategy Dimensions of Product Innovation Strategy

\begin{tabular}{|c|c|c|c|c|c|c|}
\hline & \multicolumn{2}{|c|}{ SBU1 } & \multicolumn{2}{|c|}{ SBU2 } & \multicolumn{2}{|c|}{ SBU3 } \\
\hline & Before & After (Realized) & Before & After (Realized) & Before & After (Intended) \\
\hline Product Focus & Modification & Diversification & Modification & Diversification & Modification & Diversification \\
\hline Customer Focus & Defensive & Offensive & Defensive & Defensive & Defensive & Offensive \\
\hline Competitor Focus & Reactive & Proactive & None & Reactive & Reactive & Proactive \\
\hline
\end{tabular}

program and work in teams. One manager explained this integration:

Before, we had a very traditional structure. We had marketing and engineering departments and within engineering we had product engineering, and within marketing we had category management, and truly our category managers were tied more to customer relations than to driving products or new product development. So, we never had a chance to do market research or other things of that nature. We had a gap in market development vs. customer need, so most of our initiatives would come out from our sales force, and our sales force being close to the customer and their perception of "Our customers need this, and this is where we think the market may be heading." We did have a product steering committee .... We still maintain the product steering committee, but what has changed is that the marketing and product development is in one entity within one organizational structure .... We no longer have a VP of Engineering, we've decided to marry it into the product development organization.

In the new organizational structure, the engineers are grouped into sustaining and advanced engineering. While sustaining engineering improves existing products through product modifications, advanced engineers develop more innovative products and explore opportunities by using newer technologies. As such, the technology use of SBU1 is synergistic. Moreover, since the advanced engineering efforts are expected to generate radical innovations, their marketing strategy for the product focus dimension is product diversification. The following quotation from a senior executive expresses SBU1's two-year vision and explains SBU1's aspirations for product diversification and synergistic technology use:

We are recognized, we are the brand leaders. We have a [a high percentage] market share. We don't have U.S. competition in our core products anymore. We are facing a fragmented, changing market, so we've got to sustain our quality. It's accepted, it's a given; we don't get credit for it, but if we fail, we will lose what is our biggest asset. We've got product development, but we have to maintain sustaining engineering. But we've got a layer in advanced engineering and innovative engineering, which links with our corporate group. Those are the people who are looking at generation $Y$, while teams are driving generation $X$. They are filling the bank, we may take some of our investment and throw it out there and we may not get a return, but we won't lose money. But we've always got cash that we can pull from and there are no gaps in the stream of innovation so that three years from now our sales force comes back saying, "We can't keep up."

To achieve radically innovative products, SBU1's top managers envision using corporate's engineering departments in addition to its own engineers. Moreover, they collaborate with third parties in the development process. This is a change from internal to external in their technology orientation dimension of innovation strategy. One senior manager explained:

Table 6: Organizational and NPD Process Changes

\begin{tabular}{lll}
\hline & \multicolumn{1}{c}{ SBU1 } & \multicolumn{1}{c}{ SBU2 } \\
\hline Organizational Change & $\begin{array}{l}\text { Top-management change. } \\
\text { Marketing and product development departments } \\
\text { have been integrated and colocated. }\end{array}$ & $\begin{array}{l}\text { Director of manufacturing services now reporting } \\
\text { to VP of marketing in addition to VP of } \\
\text { operations. } \\
\text { An NPD program manager is hired. }\end{array}$ \\
NPD Process Change & $\begin{array}{l}\text { Three stages are added to the front end of the old } \\
\text { NPD process. }\end{array}$ & $\begin{array}{l}\text { NPD procedures have been documented. } \\
\text { Time schedules for each NPD project are being } \\
\text { imposed. } \\
\text { A formal product launch procedure is being } \\
\text { implemented. }\end{array}$ \\
\hline
\end{tabular}


There are certainly no resources for advanced engineering. You can hardly get resources torn away long enough to do your product engineering. So, what structure I'm putting into place? These product teams are all focused on business settings and are dedicated teams and their number one goal being product development. Advanced engineering will be a way to accomplish that .... We want to use [corporate] $R \& D$ to begin the advancement. So, when these product teams are finished working on this year, they go to [corporate] $R \& D$ and get these concepts that have already been a fair amount of engineering done. It's the upfront part of any design that you can't really put a time limit on... The more time we can dedicate to that advanced engineering .... We've got marketing issues to worry about. So, we don't have the luxury of having a staff of engineers. We can't afford that.

Finally, SBU1's new innovation strategy embodies a change in the customer focus component of their marketing strategy. In their innovation efforts, they will target not only their existing customers but also the customers currently served by their competitors. Furthermore, SBU1 envisions itself as being ahead of the competitors by focusing on research and development. This presents a change in their perspective of competitor focus from being reactive to proactive. While elaborating on SBU1's five-year vision, one senior manager explained SBU1's intended shift in customer and competitor foci:

In aggregate, 7 teams are putting out 10 products a year, and it's in these channels, this retail and these customer foci, and this channel wholesale, and we are concentrating on these local markets, and we are going after this competitor and knocking them out, so they're defensive, not offensive, and we are reinventing ourselves. Five years from now, that's just the way we do business.

\section{$S B U 2$}

SBU2 faces competition from both regional and national firms. Management indicates that their customers are very sensitive to price, so SBU2 differentiates itself via service by delivering built-to-order products quickly. The problem with this competitive strategy is that it results in high inventory levels and the proliferation of stock keeping unit (SKU) numbers.

SBU2 was defensive in its customer focus and had not been innovating before the corporate strategy change. They have only been launching slight modi- fications of their existing products. Once corporate mandated the new innovation strategy, SBU2 adopted a fast follower strategy where they aim to develop products that have been proven to be successful in the industry. In effect, SBU2 has changed from not having a customer focus to a defensive strategy. One manager described this:

\begin{abstract}
We began introducing products our competition had already introduced, so we just caught up .... They were going to be home runs. The philosophy we have developed is not to be the leading edge company. If you look at the product life cycle curve, we want to be in the upper one third (i.e., rapid follower).
\end{abstract}

In addition to adding modifications to their existing product lines, they are also introducing new product lines, which represent a change in their product focus from modification to diversification. One manager described SBU2 introducing a new line:

So, finally [SBU2] could come up with something that could be conceived as innovative ... This has been our [corporate] strategy also, which really makes it very difficult when people are putting pressure on you to innovate, but your whole strategy is to be a fast follower. So, finally we can be a fast follower with those types of items, but we can innovate in how we put it together and how we present it.

It is worthwhile to note that despite the introduction of the new line, SBU2's product strategy cannot be categorized totally as product diversification because the components in this new line are modifications of existing products. The innovation, as the manager described it, is the unique combination of existing and modified components.

Before the corporate mandate was communicated, SBU2 did not have a competitor focus. However, they adapted to corporate's new innovation strategy by adopting a reactive competitive stance. They simply started responding to customers' requests accumulated at periodic meetings with major customers. In these meetings, marketing personnel from SBU2 explain trends to customers, inform customers of the changes made based on the previous year's comments, ask for product improvement suggestions, and discuss new product ideas. They also conduct marketing research regarding communications (e.g., type of promotions, sales and marketing aids). One manager described these meetings: 
We have one each week and we have them in different regions .... We invite customers based on what our regional directors are recommending to us. They are the key customers in that area and that the sales people have a lot of confidence in and can help direct us the right way .... [The customers] are starting to recommend higher-level people in their organization to come and things like that. So, they are starting to figure out that "people are really listening to what we are telling them at these things" .... And we go through what we've done and how that was supported by what they basically told us the last time. Then, we go through what type of product improvements they would like to see .... Then, we go into new product ideas, SKU specific items. So, whether it's [one product] or [another product] that we haven't had in line because we are really losing business if we don't have it. Specific things like that .... Then, we list all the ideas ... and prioritize them .... We walk away from there with a [regional] group of priorities .... We look at [regional priorities] separately, and then look at them together and try to figure out what the priorities should be for a national company.

Prior to the corporate strategy change, SBU2 lacked a formal NPD process. They did not have program management, a true fuzzy front end management, or a formal launch procedure. For example, they had no time schedules and launch dates. In the meantime, the competitors of SBU2 had introduced new products, so SBU2 fell behind. The following quotation from a senior manager illustrates:

Up until three years ago, we introduced very little new product here, we were known as a tired company that was not innovative. Our competition caught up and passed us .... We brought on [the program manager], we didn't have program managing. There was no fuzzy front end; we just started. There was no front end designing, then detailing out what had to happen, and assigning responsibilities and establishing a timeline and working toward our launch date. We just worked on it and when it was complete, it would be launched; there was no striving toward a set date.

Since there was no formal NPD process in place before the corporate mandate, marketing and engineering departments were "throwing projects over the wall" during product development. Also, the R\&D efforts for new products were mainly within the established area of technology. Hence, technology use was isolated. Moreover, technology orientation was internal as they relied solely on their own employees for NPD. To conform to the corporate mandate to innovate, SBU2 recently initiated a formal NPD process. However, they made no changes in their technology use and orientation but rather put more pressure on existing human resources. One senior manager described these changes:

\begin{abstract}
When the request came to me saying that we had to hire more engineers, I said, "You're crazy." I want these engineers that are only working about 20 or $30 \%$ of the time working $110 \%$ of the time. During the time of launch, yes, they would be expected to work overtime, when the projects are maturing. Then, they can drop back off to normal workload when they are leading up to that point. So, we are requiring a lot more from them.
\end{abstract}

Finally, they made some organizational changes. SBU2 did hire a midlevel NPD program manager to implement the NPD process. They also created a director position to report to both the vice president (VP) of manufacturing and the VP of marketing. This director supervises the NPD projects, improves communication between engineers and marketers, and resolves conflicts.

\section{SBU3}

SBU3 operates in a mature industry with several other established firms and sells the vast majority of its products through one retail outlet only. Contrary to its competitors' positioning, SBU3 has always targeted the premium segment. The executives indicate that their goal is to maintain their successful performance while continuing to operate only in the premium segment. Although they know they can pursue the broader market through lower prices, they choose not to do so. They pass opportunities that could damage their image as a premium product manufacturer, even if the opportunity may be financially positive in the short run. In terms of the customer focus dimension of their marketing strategy, they are defensive. One manager explained:

[A competitor] will sell you five, six, seven different levels of [product type]. So, what are they saying? "OK, well, we've got this high priced [product], and only so many people will buy it, and we need it \$2 lower for somebody else and \$3 lower for somebody else".... We haven't done that here. Now, how long will it stay 
like this? I don't know that, but [we've] resisted the temptation.

Despite their current customer focus, they intend to offer products that may enable them to capture additional market share and to serve new customers within the same segment by expanding into other retail outlets. This expansion hinges on their R\&D efforts in a new, potentially disruptive technology, which may yield opportunities to develop highly innovative products in the near future. Consequently the intended long-term strategy (Mintzberg and Waters, 1985) of SBU is categorized as offensive.

Although they introduced product modifications in the past, they recently launched a merchandising innovation. The innovation has been successful, as it has lowered the retailers' costs by allowing customers to choose products with less assistance from sales staff while simultaneously increasing the amount of product sold. As such, SBU3 is currently pursuing product diversification in terms of the product focus component of their marketing strategy.

Their competitor focus was reactive, as they would normally counter competitors' new products by introducing a similar but higher-quality product. Currently, due to corporate's emphasis on innovation, the R\&D department is empowered more than ever and works on innovations that will provide a competitive edge. SBU3 is thus becoming more proactive in competitor focus.

SBU3 has a very informal and entrepreneurial culture, so they are not highly structured. One manager described SBU3 as a "hallway company." This same manager also indicated that, because the average industry experience of the senior managers is $20-25$ years, they tend to be largely intuitive in their decision making. This intuitive style is also exhibited in their product development approach: They have no explicit NPD process. The following quotation is a response to the question of "Does R\&D make a formal presentation to the executive team when they identify a new product idea?":

We are very informal about all this. If I want to talk to anybody in this company, I don't normally wait for the meeting, I go down and talk to them .... I'm not trying to be funny about it, but that's the nature of the entrepreneurial culture we have. We won't want to change that.

Even though one year has passed since corporate communicated the new innovation goals, SBU3 has not changed its NPD approach. The only noticeable event was the introduction of a merchandising innovation. As indicated earlier, SBU3 is exploring opportunities in new technologies that are expected to result in new products. SBU3 expects that it will introduce new products using the new technology or a combination of new and old technologies, so their technology use has shifted from isolated to synergistic.

They are currently working with experts outside the firm to develop new products, as was the case for the merchandising innovation they recently introduced. Consequently, their technology orientation has also shifted from sole reliance on their own R\&D personnel to involvement of external experts.

\section{Discussion of the Similarities and Differences between the Cases}

In the collective case study presented in this article, despite operating under the same corporate PIC, the SBU managers seem to have interpreted the new PIC differently. Consequently, similar to the extant literature (e.g., Firth and Narayanan, 1996), these casestudy firms are implementing different NPD strategies. This conclusion is further confirmed by the survey responses. As summarized in Table 7, the average scores indicate that the match between corporate and SBU innovation objectives are perceived as moderately high at SBU1 and SBU3. However, the responses from SBU2 point out a mismatch between corporate's overarching innovation strategy and the division-level innovation strategy of SBU2.

Why would SBU1 charter into unexplored seas by planning to develop radically new products, while SBU2 introduced new products that merely allowed it to catch up with its competitors? Why is SBU3 seemingly not responding to changes in the corporate mission? There are, of course, a variety of factors that play a role in explaining why the three SBUs interpreted and implemented the new strategy differently. In this section, the observations gleaned from the indepth interviews are enunciated.

\section{Observation 1: Past Performance and Strategic Typology Drive Innovation Strategy}

Firms adapt to their environment via the strategic choices they make (Miles et al., 1978). In adapting to the environment, firms tend to employ one of several 
Table 7: Average Responses to Selected Survey Items

\begin{tabular}{|c|c|c|c|}
\hline$($ strongly disagree $=0$, strongly agree $=10)$ & SBU1 & SBU2 & SBU3 \\
\hline Match between Corporate and SBU Innovation Objectives & 7.4 & 4.0 & 6.7 \\
\hline Adaptiveness of NPD Strategy to Competitive Environment Changes & 7.0 & 6.0 & 8.7 \\
\hline Use of Informal Scoring Methods to Track Innovation Projects & 6.0 & 5.0 & 4.0 \\
\hline Have Specific Metrics to Monitor and Control Research & 4.5 & 0.0 & 5.0 \\
\hline Have Specific Metrics to Monitor and Control NPD & 8.0 & 6.5 & 4.7 \\
\hline Have Specific Metrics to Monitor and Control Product Launch & 9.0 & 6.5 & 4.3 \\
\hline
\end{tabular}

unique strategies and associated tactics in approaching the target market. Miles et al. (1978) label the four strategic types as defender, analyzer, prospector, and reactor. Three of these strategy types are exhibited by the firms in this study (none exhibit the prospector strategy).

Among the case-study firms, SBU3 is a defender. Defenders stake out a market segment that allows them to focus on a stable set of customers and products so that they can maintain control of the organization and operate as efficiently as possible. SBU3 targets the high end of the market by producing only premium-priced products that are sold primarily through a single retailer. The choice of which new products to develop is made by the senior managers, while NPD is implemented via a functional matrix structure in which a project manager with limited authority coordinates activities and schedules across different functional areas (Larson and Gobeli, 1988). This firm has been very successful with this niche strategy, experiencing $30 \%$ top-line growth for the last 20 years.

SBU1 is an analyzer in that they attempt to minimize risk by maintaining a stable core of products and customers while simultaneously attempting to maximize the opportunity for profit by introducing multiple new products to their existing market. NPD is implemented via a project matrix structure where the team has responsibility for the outcome. A manager at SBU1 noted:

\section{Within the product team environment, we want them to think of and act like a little business and make all the right decisions for that business.}

This firm also has been successful in the past. They are recognized as brand leaders in the segments in which they compete and they enjoy market share dominance.

Finally, SBU2 is classified as a reactor, a firm that exhibits inconsistent and unstable adjustments to the environment. SBU2 differentiates itself with rapid de- livery of built-to-order products, a strategy that requires high inventory levels. In addition, they have contractual obligations to supply certain existing product lines for 10 years, resulting in a huge increase in the number of SKUs they must stock. Consequently, they have high inventory carrying costs, are lacking warehouse space to store components, and are running out of part numbers available for new products due to system constraints. These constraints are not only costly but also have affected SBU2's ability to launch new products. The inconsistent responses to environmental change have resulted in poor performance and reluctance to act aggressively in NPD.

Choices associated with the strategic types are designed to address entrepreneurial, engineering, and administrative types of problems (Miles et al., 1978). In the entrepreneurial problem, firms identify their organizational domain in terms of the product or service industries in which they compete and the specific markets they target. The engineering problem identifies the tactics firms use to compete in their domain and thus operationalizes the solution to the entrepreneurial problem. Finally, the administrative problem involves rationalizing and stabilizing the activities that successfully solved the entrepreneurial and engineering problems. That is, firms identify and improve on the activities at which they excel while at the same time limiting standardization's negative impact on innovation. To address this delicate balance between efficiency and innovation, Ramanujam and Mensch (1985) suggest that senior management should identify and communicate an innovation strategy. That is, within the firm's chosen domain, management should consciously choose whether to lead or follow - whether to dominate the target market or to maintain a smaller share. This position, in turn, drives the innovation strategy pursued in terms of focus (product, process, or service) and aggressiveness (incremental to radical).

Based on their past success and their dominance of their target market segments, leading is a realistic option for SBU1 and SBU3 because their market share 
dominance and profitability provides them the resources to experiment with innovation. In fact, both divisions have chosen to continue to dominate their current markets or market niches while also pursuing other opportunities such as introducing new products or expanding their customer base. On the other hand, SBU2 has chosen a follower strategy because it is less risky to imitate the competition.

Pursuing innovation leadership fits with SBU1's analyzer strategy. The following quotation illustrates that the market leadership for which they are recognized comes from the quality of their products:

Our strength, and what we need to maintain as our strength, is our ability to make quality products.

To support product quality, they assign engineers to each product to maintain sustaining engineering using the same processes that were used in the past. At the same, their innovation strategy is that of product innovations that lean toward the radical end of the continuum, which are developed by cross-functional, colocated teams using a Stage-Gate ${ }^{\circledR}$ process. Thus, the processes and functions of sustaining existing products and developing new products are separated to maintain role clarity.

Ultimately, SBU1's innovation strategy is to develop radical innovations in the form of new products that fulfill the latent needs of their customers. The following quote from one senior manager demonstrates that the new products are not simple modifications of previous products:

Sometimes ideas that come from customers aren't neatly packaged. More often, I think, they'll tell you what the product needs to do for them versus what the product should be. A lot of our categories are very mature and there certainly isn't a lot of innovation, so I don't expect ideas to come neatly packaged from the customer in these categories. In the innovation, I thought about it as more we are going to create what they don't know they want yet. That's the idea.

As expected of a defender, SBU3 is moving slowly in developing an innovation strategy. They continue to protect their core market by continuing to develop only premium-priced products with the same NPD routines they have been using in the past. However, they are aware of technology changes in the broader environment and, at the same time, are responding to the mandated innovation charter by focusing on radical nonproduct innovations. The first innovation they implemented affects the purchasing process of the end users. This successful merchandising innovation helps end users visualize the final outcome of their purchase choice, thereby minimizing the risk of dissatisfaction.

In the longer term, SBU3 is investigating new technology that will affect raw material sourcing and their manufacturing processes. This new technology should result in a higher-quality product but is not likely to exhibit new features or benefits that are radically different from the end users' perspective.

Finally, SBU2 reacted to their poor competitive position and the mandated innovation charter by implementing an incremental product innovation strategy. Prior to the innovation charter change, SBU2 introduced very few new products and fell behind the competition that did regularly introduce new products. In response to the mandated innovation charter, SBU2 began imitating competitors' new products. However, this competitor-driven innovation strategy has been problematic. Although their competitive position improved, the strategy has led to the negative operational consequences described earlier. Ultimately, SBU2 needs to choose appropriate innovation strategies to improve its performance.

\section{Observation 2: Capacity Constraints Influence Innovation Strategy toward Process Innovation in Mature Industries}

Innovation strategy is shaped by the firm's strategic direction as well as by the business environment. As industries approach maturity, the focus of innovation shifts toward process innovations (Utterback and $\mathrm{Ab}$ ernathy, 1975). Though all three subsidiaries studied operate in mature industries, they have adopted very divergent innovation strategies. SBU2 and SBU3 have located themselves at opposite ends of the spectrum. Whereas SBU2 is focusing more on process innovations, management at SBU3 is investigating application opportunities of a novel technology in hopes of generating radically innovative products in the future. SBU1, on the other hand, seems to have found a balance between product and process innovations in terms of allocating its resources. They are executing organizational changes, such as integrating $R \& D$ and marketing, introducing a channel member position to enhance acquisition and transfer of information on the observed and latent needs of customers, and adding new steps to their NPD process. 
Why would SBU2 focus on process innovations as Utterback and Abernathy (1975) prescribe while SBU3 plans to explore radical innovations, although both are in mature industries? Ramanujam and Mensch (1985) suggest an explanation for the underlying reason for the actions of SBU3: If the new technology proves useful, then even in a mature business, superior margins could result for those firms that are able to initiate or quickly adopt the use of the disruptive technology. The core competency of SBU3 has been its R\&D skills. Management now intends to leverage this capability to generate long-term advantage (Prahalad and Hamel, 1990). Further, they expect to build entry barriers when their experimentation with the new technology results in patents (Porter, 1980).

However, the literature does not suggest any explanations why SBU2 would show such a dramatic shift toward process innovation. Based on the insights gleaned from the interviews at SBU2, in addition to cost pressures, there is another reason why firms in mature industries shift towards process innovations: capacity constraints. The following quotation suggests that senior management at SBU2 deem process innovations as a higher priority over product innovations due to capacity constraints:

\section{We have to balance, now that we have maximized ca- pacity of our company, we have fantastic numbers, but we have a capacity constraint. What I am working on now is the engineering side [rather] than on the product side. We have to build/expand plants. You reach a point that you have to stop packing it in or your service will be jeopardized. And it is our service that is our most valuable asset to customers. And if that slides, we are just the same as everyone else. We have got more into [a product feature], things that were five years ago unheard of to us. We introduced [same product fea- ture] this year, and it is very successful, and we have had to delay some projects, because we don't have ca- pacity.}

Corporate change occurs in phases (Duck, 2001). The determination phase, which takes place after implementation, is pivotal because when implementation ends, firms often experience change fatigue, especially if the implementation has not gone as expected. In the next stage, determination, the firm faces the critical decision of quitting or continuing on its change journey. If a firm shows determination to continue in this phase, it is likely to reach its change objectives. One prescription to firms in the determination stage is to acknowledge and address setbacks and to keep employee morale high. Having implemented a new NPD process, SBU2 has reached the determination phase of change. The following quotation from one manager demonstrates that management at SBU2 acknowledges the hurdle and identifies that they need to build plants to alleviate the capacity constraint problem and continue to change:

If it weren't for capacity constraints and things, we would be getting better, but we have kind of hit a wall .... We have been introducing things at such a rate, and they build parts for every product, for example, [facility name] makes [a component], which gets shared between styles .... Month after month their outputs are getting closer and closer to their limit.

Consequently, capacity constraints have tipped the innovation strategy balance toward process innovation at SBU2. SBU2 is having problems in terms of deciding which product to develop next because even though a project might have higher priority for customers, it gets delayed because the resulting product requires too many SKUs and requires system capacity as well as storage. This is in sharp contrast to SBU1, which does not confront capacity constraints and therefore can allocate its resources to both product and process innovations.

\section{Observation 3: Change Results from Senior- Management Involvement in Day-to-Day Implementation}

Successful innovations require product champions (Montoya-Weiss and Calantone, 1994). Given their influential positions and access to external information, senior managers often champion product ideas, but their ability to influence successful outcomes varies. Prior research suggests that senior-management influence on product innovations is explained by several variables, including expertise in the functional areas of general management, marketing, $R \& D$, production, and even finance, with marketing expertise dominating the effects among these functional areas (Hoffman and Hegarty, 1993). Beyond functional expertise, the specific actions in which senior managers engage also explain how they influence product innovations (Elenkov, Judge, and Wright, 2005). In addition to their close connection to the external environment and the power to advance initiatives based on hierarchical position, senior managers also influence innovation by creating and communicating 
an exciting view of the future; by selecting, rewarding, and supporting midlevel managers; and by creating a culture that rewards innovation.

The case studies support this prior research and add insight into the processes through which senior managers influence innovation. At SBU1, a new senior manager was brought in to the firm to implement process changes in NPD. This management change seems to have triggered many of the structural and process changes that were implemented. For example, the new executive at SBU1 came with experience in an industry where "customer is king" and therefore is very sensitive to customer input in product development. In fact, he says:

\section{We want the customer in every part of the development phase.}

To improve the accuracy of information gathered from the customer, this executive created a position in the marketing department whose responsibility is to be independent of the salesperson and provide contact between the marketing department and the customers. They deliver customer needs and ideas gathered from the customer to the marketing department, resulting in a greater voice of the customer in product development and improvement of product definition accuracy. Getting the product definition right is one of the keys to new product success (Cooper, 1994). Moreover, when new product concepts are generated, these dedicated personnel get customer feedback on these concepts in a more timely and accurate manner as well as serve as the means to identify latent needs of customers.

Equally important is the active role this new executive plays in the implementation of the new process. He restructured the innovation process by combining the marketing and engineering departments, which he now manages. He and his top-management team are implementing multiple information technology improvements to enhance communication and incorporate leading-edge systems in the NPD process. Finally, he acknowledges that, as a newcomer, he must work within the confines of the existing culture as he recreates it to focus more on innovation:

I used to work at other places where we used to get rid of top-level people and start on day two .... This place is a lot more considerate of the employees and their attitudes.
However, recreating a culture is not easy. This executive finds that he is getting resistance to change because the process is so new:

This is a new process, foundation, structure. Nobody knows what they are being asked to do. This is the first time they are being asked to do everything.

To overcome this resistance, he finds that he needs to implement the changes slowly by first building consensus. In addition, he says his role is crucial in ensuring managers and employees understand the processes and implement them correctly. Doing so is not an easy process:

I have to be in everything, I have to explain everything to everybody. I have to explain everything to everybody. I have to provide an example for anybody to do. It's just pain staking. It's muscle driven.

At the other two firms, the senior managers implementing the changes are the same managers that have been with the firm for several years. SBU2 did hire a midlevel engineering manager to implement the new NPD process. Consequently, customer input is incorporated in NPD activities differently at SBU2. As indicated earlier, this subsidiary would like to make sure that the new products introduced are "sure to sell." They do two things to ensure this. One is that they only introduce the successful new products that were pioneered by either sister companies or competitors. The other is that they get customer feedback via the regional customer meetings described previously. In effect, the marketing department gets the customers' blessing on every new product regardless of the NPD stage: for new product ideas before development, for prototypes that are about to be produced, and for the promotions under preparation for products about to be commercialized.

To successfully implement their NPD process, this firm trained engineers on the new project management software to help employees juggle multiple tasks and projects simultaneously. Like SBU1, the senior manager and the new midlevel engineering manager invested considerable time and effort in explaining and implementing the new processes, particularly the new software brought in to manage projects and highlight the critical path. They did so by giving step-by-step classes and by following through with implementation: 
It is classes, it is projecting up on the screen and everyone else having their computers and following along. And, it isn't just: "We are going to use [this software], good luck guys, here is your book." That doesn't work. So, we recognized the need there, and that we had to train people, instead of just throwing them out there. And relentless use, just relentless .... No excuses, you just do it.

In addition to training, SBU2 focused on compliance with the new process rather than attempting to build consensus as did SBU1. As the senior manager at SBU2 indicated, in meetings where the project timeline was discussed:

\section{Our motto became, "You will hit the date."}

To create compliance with the new NPD process, this SBU also modified expectations of its engineers' performance. In the past, engineers tended to work on only one project that didn't have a completion date. Under the new NPD system, not only are there completion dates, but engineers are also expected to work on multiple projects at the same time. Those who have not been able to adapt have been terminated:

Four or five years ago, one engineer, one project and you could do a pretty good job of keeping it all in your mind. Especially, when [we] didn't have a launch date. It is also holding people accountable and understanding that there will be a price to pay if you don't do a good job. We have terminated engineers for not being able to adapt.

Collins (2001) likens change to pushing a heavy flywheel constantly in a consistent direction over a long period of time. What is seen in these SBUs is that senior-management involvement in pushing the flywheel is integral, especially in the beginning of change, when the direction is to be set.

\section{Observation 4: Use of a Single SBU Performance Metric is Insufficient for Achieving Fundamental Change in Strategy}

Once the innovation strategy is set, one of the ongoing responsibilities of senior management is to evaluate outcomes and performance. Organizational control is any process by which managers direct attention, motivate, and encourage organizational members to act in desired ways to meet the firm's objectives (Eisenhardt, 1985; Ouchi, 1979). The type of control plays an important role in terms of evaluating performance. Among the various types of control are structural (also referred to as bureaucratic or behavior control), market (Ouchi, 1979; Williamson, 1975), cultural (Arvey, 1979), input (Mintzberg, 1979), and output (Jaworski, 1988). For these three SBUs, corporate has imposed only one type of control: Output control in the form of a metric requiring that a certain percentage of the SBU annual revenue results from products introduced within a predetermined number of months. In these case studies, it is seen that this metric influences the innovation strategies adopted at the three SBUs.

Before the corporate mandate, SBU1 had been introducing new products. Although they had a much smaller-scale NPD program, they were in conformity with the performance measure when it was first imposed. This head start allowed them to focus their resources in transforming the processes in addition to tackling newer product innovation and to focusing on longer-term innovation goals. An improved NPD process meant that they could introduce products more quickly in the medium to long run. For example, reduction in NPD cycle time is a major driver for the changes made in the NPD process:

I'm giving them all these parameters so they are more focused and they develop quickly. The previous process, because it didn't have a definition, just took way too long and they were missing too many opportunities. The opportunity would be there when they began, but by the time the product came out, the opportunity had changed.

In contrast to SBU1, the effect of the metric on SBU2 and SBU3 has been different, both of which are developing line extensions and merchandising innovations to conform to the metric. When the new metric was mandated, SBU2 had not been introducing new products so they had to begin introducing new products quickly to perform to the standard. As a result, smaller and easier-to-do projects were implemented. Such projects provide lower value to firms than do larger and more difficult projects (Cooper and Edgett, 2003). In this study, another downside of this "picking-the-low-hanging-fruit" strategy is seen: SBU2's short-term orientation resulted in a deadlock for new product introduction because they exhausted the available supply of part numbers by introducing multiple product extensions.

Conforming to the performance metrics has had a smaller effect at SBU3, which quickly introduced 
merchandising innovations that were in the pipeline already. However, they refrained from implementing product extensions merely to comply with the metric. Instead, they are exploring different technologies in a deliberate manner.

Although requiring that new products yield a certain proportion of total firm revenues is a common practice in firms (Cooper, 1994; Cooper and Kleinschmidt, 1995), it appears to have mixed operational value in SBU2. There are two remedies to alleviate the negative consequences of the performance measures imposed by corporate. The first is to impose a different measure that could facilitate process as well as product innovations. For example, McGrath and Romeri (1994) propose "the R\&D effectiveness index" as an alternative. The effectiveness index computes the ratio of increased profits from new products divided by the investments in product development. More specifically, the index is computed as (\% New Product Revenue) $\times($ Net Profit $\%+R \& D \%) \div($ R\&D \%), where the percentages are stated as a percentage of revenue. When the index is larger than 1.0, the return from new products is greater than the investment. In the case of the SBUs studied, this measure seems to be a better metric as it incorporates development costs by including net profit in the calculation. This metric would have encouraged SBU3 to begin executing a structured NPD process to introduce the new products as efficiently as possible.

Another solution is to impose additional output controls or behavior controls. For example, the number of new patents acquired could encourage more radical innovations. This, in turn, would have made it more likely for SBU2 to adopt a longer-term perspective before rushing to market with line extensions only. A further control mechanism would be to employ multiple time horizons for the output control. Knowing that the consequences of not being able to meet the shorter-term objectives would not be so unpleasant, SBU2 managers might have focused on achieving longer-term goals.

Furthermore, input controls such as the number of R\&D and marketing personnel that hold membership in professional organizations, rewarding scientists for publishing in journals, implementing free time for engineers and scientists to work on their own projects, and awarding other innovative achievements could have facilitated SBU2 in thinking in terms of a longterm innovation strategy.

Finally, a metrics thermostat for NPD activities at the corporate level would help align the innovation objectives of corporate and SBU2. Hauser (2001) refers to an adaptive control method to adjust priorities on a firm's chosen metrics as a metrics thermostat. By adjusting the implicit weights, a metrics thermostat can enable corporate to control the innovation activities of its SBUs without explicitly dictating detailed actions to reach the desired goals.

In summary, the use of a single, standard metric for evaluating innovation performance is not sufficient since each SBU will be positioned differently at the starting point of the change mandate and may go off track just to conform to the metric.

\section{Conclusion}

Breaking established practices and old habits is difficult in organizations that need change, especially if those practices led to successful results in the past. Moreover, change is a cumbersome process and does not occur smoothly even when there is a clear mandate for change. Both of these phenomena are observed in this study when investigating how three SBUs of a corporation were responding to the ordered strategy change of abandoning growth via mergers and acquisitions and adopting a growth strategy via new product development. This study is unique in that both the changes that were taking place immediately after the mandate and mediumto-long-term changes managers were contemplating were observed. Consequently, after summarizing the climate at the three SBUs before the mandate and the changes that were being made and their vision of the future, some common practices for enhanced success and some practices to avoid for undesired results are uncovered.

Two caveats of this study are noteworthy at the outset. First, at most three managers were interviewed at each firm for a limited amount of time. Also, reliance on the perceptions and recollections of managers about how things have happened should be noted. However, as case studies offer the opportunity to provide valuable points of view (Bonoma, 1985), that judgment gained from the three cases in this study would provide useful insights for managers, especially those who are in the midst of innovation strategy change.

In the cases studied of firms operating in non-hightech, traditional industries, several factors have been observed to influence the formulation of a new innovation strategy. First, past performance and strategic 
typology constrain the innovation paths available. Poor past performance limits available resources while the strategic typology management uses limits their ability to recognize other opportunities. Second, not only are capacity constraints manifestation of limited resources, but their salience to managers also provides a catalyst in moving toward process improvements. Next, management involvement in the day-to-day implementation of change is necessary to ensure that the new processes are implemented. Overcoming the ingrained and habitual nature of prior modus operandi is tedious and time-consuming work, especially when the existing culture leans toward consensus building. Finally, corporate performance metrics are quite influential in how SBUs adapt to change. Perhaps the most prominent finding of this study is to clearly identify that even with the immense power corporate has over these SBUs, some can still dance to their own tune ignorant of their own deviation because the metric is not sufficient to detect these deviations. Though simple metrics are useful in that they are easy to understand, they also may result in shortterm responses that ultimately harm the firm. In this regard, multiple types of metrics would minimize the likelihood of nearsighted responses to innovation charter changes.

\section{References}

Abrahamson, E. (2004). Change without Pain: How Managers Can Overcome Initiative Overload, Organizational Chaos, and Employee Burnout. Boston: Harvard Business School Press.

Arvey, R.D. (1979). Fairness in Selecting Employees. Reading, MA: Addison Wesley.

Barczak, G. (1995). New Product Strategy, Structure, Process, and Performance in the Telecommunications Industry. Journal of Product Innovation Management 12(3):224-234.

Belasco, J.A. (1990). Teaching the Elephant to Dance: Empowering Change in Your Organization. New York: Crown Publishers.

Bonoma, T.V. (1985). Case Research in Marketing: Opportunities, Problems, and a Process. Journal of Marketing Research 22(2):199208.

Clark, K.B. and Wheelwright, S.C. (1993). Managing New Product and Process Development. New York: Free Press.

Collins, J. (2001). Good to Great: Why Some Companies Make the Leap ... and Others Don't. New York: HarperCollins.

Cooper, R.G. (1993). Winning at New Products: Accelerating the Process from Idea to Launch ( $2 \mathrm{~d}$ ed.). Reading, MA: Addison-Wesley.

Cooper, R.G. (1994). Debunking the Myths of New Product Development. Research Technology Management 37(4):40-50.

Cooper, R.G. and Edgett, S.J (2003). Overcoming the Crunch in Resources for New Product Development. Research Technology Management 46(3):48-58.

Cooper, R.G., Edgett, S.J., and Kleinschmidt, E.J. (2001). Portfolio Management for New Products (2d ed.). Cambridge, MA: Perseus Publishing.
Cooper, R.G. and Kleinschmidt, E.J. (1995). Benchmarking the Firm's Critical Success Factors in New Product Development. Journal of Product Innovation Management 12(5):374-391.

Crawford, C.M. (1980). Defining the Charter for Product Innovation. Sloan Management Review 22(1):3-12.

Cresswell, J.W. (1997). Qualitative Inquiry and Research Design: Choosing Among Five Traditions. Thousand Oaks, CA: Sage Publications.

de Geus, A. (1997). The Living Company: Habits for Survival in a Turbulent Business Environment. Boston: Harvard Business School Press.

Duck, J.D. (2001). The Change Monster: The Human Forces that Fuel or Foil Corporate Transformation and Change. New York: Crown Business.

Eisenhardt, K.M. (1985). Control: Organizational and Economic Approaches. Management Science 31(2):134-149.

Eisenhardt, K.M. (1989). Building Theories from Case Study Research. Academy of Management Review 14(4):532-550.

Elenkov, D.S., Judge, W., and Wright, P. (2005). Strategic Leadership and Executive Innovation Influence: An International Multi-cluster Comparative Study. Strategic Management Journal 26(7):665-682.

Firth, R.W. and Narayanan, V.K. (1996). New Product Strategies of Large, Dominant Product Manufacturing Firms: An Exploratory Analysis. Journal of Product Innovation Management 13(4):334 347.

Ginsberg, A. and Venkatraman, N. (1985). Contingency Perspectives of Organizational Strategy: A Critical Review of the Empirical Research. Academy of Management Review 10(3):421-434.

Hauser, J.R. (2001). Metrics Thermostat. Journal of Product Innovation Management 18(3):134-153.

Hoffman, R.C. and Hegarty, W.H. (1993). Top Management Influence on Innovations: Effects of Executive Characteristics and Social Culture. Journal of Management 19(3):549-574.

Jaworski, B.J. (1988). Toward a Theory of Marketing Control. Journal of Marketing 52(3):23-39.

Larson, E.W. and Gobeli, D.H. (1988). Organizing for Product Development Projects. Journal of Product Innovation Management 5(3):180-190.

Leonard-Barton, D. (1992). Core Capabilities and Core Rigidities: A Paradox in Managing New Product Development. Strategic Management Journal 13:111-125 (Summer).

March, J.G. (1991). Exploration and Exploitation in Organizational Learning. Organization Science 2(2):71-78.

McGrath, M.E. (2001). Product Strategy for High Technology Companies: Accelerating Your Business to Web Speed (2d ed.). New York: McGraw-Hill.

McGrath, M.E. and Romeri, M.N. (1994). The R\&D Effectiveness Index: A Metric for Product Development Performance. Journal of Product Innovation Management 11(3):213-220.

Meyer, M.H. and Roberts, E.B. (1986). New Product Strategy in Small Technology-Based Firms: A Pilot Study. Management Science 32(7):806-821.

Miles, R.E., Snow, C.C., Meyer, A.D., and Coleman, H.J. Jr. (1978). Organizational Strategy, Structure, and Process. Academy of Management Review 3(3):546-562.

Miller, D. (1991). Stale in the Saddle: CEO Tenure and the Match between Organization and Environment. Management Science 37(1):34-52.

Mintzberg, H. (1979). The Structuring of Organizations. Englewood Cliffs, NJ: Prentice-Hall.

Mintzberg, H. and Waters, J.A. (1985). Of Strategies, Deliberate and Emergent. Strategic Management Journal 6(3):257-272.

Mintzberg, H., Lampel, J., Quinn, J.B., and Ghosal, S. (2003). The Strategy Process: Concepts, Contexts, Cases. Upper Saddle River, NJ: Prentice-Hall. 
Montoya-Weiss, M.M. and Calantone, R. (1994). Determinants of New Product Performance: A Review and Meta-Analysis. Journal of Product Innovation Management 11(5):397-417.

Nystrom, H. (1985). Product Development Strategy: An Integration of Technology and Marketing. Journal of Product Innovation Management 2(1):25-33.

Ouchi, W.G. (1979). A Conceptual Framework for the Design of Organizational Control Mechanisms. Administrative Science Quarterly 25(9):833-848.

Porter, M.E. (1980). Competitive Strategy: Techniques for Analyzing Industries and Competitors. New York: Free Press.

Prahalad, C.K. and Hamel, G. (1990). The Core Competence of the Corporation. Harvard Business Review 68(3):79-91.

Ramanujam, V. and Mensch, G.O. (1985). Improving the Strategy-Innovation Link. Journal of Product Innovation Management 2(4):213-223.

Seidman, I. (1998). Interviewing as Qualitative Research (2d ed.). New York: Teachers College.

Stake, R. (1995). The Art of Case Study Research. Thousand Oaks, CA: Sage Publications.
Tushman, M.L., Anderson, P.C., and O'Reilly, C. (1997). Technology Cycles, Innovation Streams, and Ambidextrous Organizations: Organization Renewal through Innovation Streams and Strategic Change. In Managing Strategic Innovation and Change, ed. M.L. Tushman, and P. Anderson, 3-23. New York: Oxford University Press.

Tushman, M.L., Newman, W.H., and Romanelli, E. (1997). Convergence and Upheaval: Managing the Unsteady Pace of Organizational Evolution. In Managing Strategic Innovation and Change, ed. M.L. Tushman, and P. Anderson, 583-594. New York: Oxford University Press.

Urban, G.L. and Hauser, J.R. (1993). Design and Marketing of New Products (2d ed.). Upper Saddle River, NJ: Prentice-Hall.

Utterback, J.M. and Abernathy, W.J. (1975). A Dynamic Model of Process and Product Innovation. Omega 3:639-656.

Williamson, O.E. (1975). Market and Hierarchies: Analysis and Antitrust Implications. New York: Free Press.

Yin, R.K. (1994). Case Study Research. Thousand Oaks, CA: Sage Publications. 